\title{
Multimodale læsepraksisser og dannelse til det digitale netværkssamfund
}

Af Anne Mette Thorhauge

Korrekt citering af denne artikel efter APA-systemet

(American Psychological Association System, 6th Edition): Thorhauge, A. M. (2018). Multimodale læsepraktsisser og dannelse til det digitale netværkssamfund.

Learning Tech - Tidsskrift for læremidler, didaktik og teknologi, (5), 10-26. DOI: 10.7146/lt.v4i5.111559 


\section{Abstract}

I denne artikel vil jeg anlægge et mediehistorisk perspektiv på læsning, skrivning og multimodale praksisser i det digitale netværkssamfund. Jeg vil argumentere for, at læsning og skrivning som forudsætning for medborgerskab må ses i relation til den aktuelle samfundskontekst, herunder de(t) dominerende mediesystem(er). Jeg vil således argumentere for, at læsning og skrivning som en 'monomodal' praksis (Kress \& van Leeuwen, 2001) har sit udspring i den moderne trykkultur, der gik forud for de elektroniske massemedier, mens fremkomsten af elektroniske såvel som digitale medier nødvendiggør en opdatering af læse- og skrivebegreberne, så de kan understøtte deltagelse og medborgerskab i et digitalt netværkssamfund.

In this article I will apply a historical perspective on reading, writing, and multimodal practices in the digital network society. I will argue that reading and writing as a prerequisite for citizenship must be seen in relation to the broader societal context, including the predominant media system(s). Accordingly, I will argue that reading and writing as 'monomodal' practices (Kress \& van Leeuwen, 2001) is based on a modern culture of print that came before the electronic massmedia, whereas the emergence of electronic as well as digital media require a redefinition of the concepts of reading and writing so they can support participation and citizenship in a digital network society. 


\section{Multimodale læsepraksisser og dannelse til det digitale netværkssamfund}

\section{Indledning}

I denne artikel vil jeg anlægge et mediehistorisk og medieteoretisk perspektiv på læsning og på multimodale læsepraksisser i et samfund domineret af digitale medier. Jeg vil argumentere for, at tilegnelsen af kommunikative færdigheder som led i dannelsen til medborger må ses i relation til den aktuelle samfundskontekst, herunder det dominerende mediesystem. Jeg vil således argumentere for, at læsning og skrivning som en 'monomodal' praksis har sit udspring i den moderne trykkultur, der gik forud for de elektroniske massemedier, mens fremkomsten af elektroniske såvel som digitale medier kalder på en opdatering af læsebegrebet, så det kan understøtte deltagelse og medborgerskab i en digital tidsalder. Jeg vil argumentere for, at forestillingerne om 'multiple literacies and multi-literacies' (Street, 2009) er relevante bud på, hvordan et sådant læsebegreb kan tage sig ud, men at det også er væsentligt at tage stilling til, hvilke vidensressourcer og samfundsmæssige handlemuligheder de skal give adgang til.

I de kommende afsnit vil jeg først skitsere den overordnede ramme for diskussionen, nemlig den aktuelle debat omkring 'digital dannelse' og de mange betydninger det dækker over. Jeg vil argumentere for, at det engelske begreb 'digital literacy' fejlagtigt er blevet oversat til 'digital dannelse', hvorved vi får blandet to niveauer sammen: de konkrete kommunikative færdigheder på den ene side og den mere overordnede dannelse, de understøtter, på den anden. I forlængelse af denne afklaring vil jeg introducere et medieteoretisk perspektiv på den mediehistoriske udvikling med udgangspunkt i Meyrowitz' periodisering af den mediehistoriske udvikling i fire epoker: den orale, den skriftlige, trykkulturen og den globale elektroniske kultur (Meyrowitz, 1994). Jeg vil sætte 
fokus på de dominerede kommunikationsformer i disse mediehistoriske epoker, herunder den tætte sammenhæng mellem skriftsproget, nationalstaten og skolen som historisk institution. I forlængelse af denne historiske rammesætning vil jeg præcisere 'multiple literacies and multi-literacies' (Street, 2009) som et udvidet perspektiv på de samfundsbærende kommunikationsformer og skitsere de alternative tilgange, dette har givet anledning til indenfor 'new literacy studies'. På dette grundlag vil jeg diskutere multimodale læsepraksisser som en alternativ vinkling på 'digital dannelse', der sætter fokus på kommunikative færdigheder som forudsætning for handling og deltagelse i netværkssamfundet.

\section{Digitale færdigheder og dannelsen til digital medborger}

'Digital dannelse' er et hot emne i tiden, og det debatteres i et væld af sammenhænge under et væld af overskrifter. For eksempel har den spektakulære sag i foråret 2018, hvor over 1000 unge mennesker blev sigtet for deling af børneporno afstedkommet en bred debat om behovet for at sætte digital dannelse på skoleskemaet ${ }^{1}$. I disse tilfælde synes vægten at ligge på børnenes og de unges evne til at omgås hinanden på etisk og forsvarlig vis, når fællesskabet bevæger sig online. I andre sammenhænge er fokus på fremtidens arbejdsmarked og de kompetencer, der vil blive efterspurgt i kommende årtier ${ }^{2}$. I disse tilfælde er vægten på tekniske kompetencer, som for eksempel evnen til at programmere. Et genkommende træk ved debatten er de mange forståelser og fortolkninger af begrebet 'digital dannelse', der i nogle tilfælde

\footnotetext{
1 Se for eksempel:

https://www.folkeskolen.dk/625757/boerne-og-ungdomsorganisationer-vilstyrke-unges-digitale-dannelse

https://www.b.dk/nationalt/organisationer-i-opraab-til-politikere-en-helgeneration-ved-ikke-hvad-der-er https://jyllands-posten.dk/indland/ECE10284156/organisationer-for-mangeunge-mangler-digital-dannelse/

2 Se for eksempel:

https://politiken.dk/debat/debatindlaeg/art5802449/B\%C3\%B8rnene-tordnerafsted-i-det-digitale-rum-men-mangler-digital-dannelse Denne forståelse af digital dannelse som fundamentale tekniske kompetencer afspejles også i de definitioner, som Center for Digital Dannelse (https://digitaldannelse.org/) og App Academy (https://appacademy.dk/) opererer med.
} 
vedrører tonen på nettet og respekten for andres privatliv, i andre tilfælde vedrører konkrete tekniske kompetencer, og andre gange igen vedrører en kritisk forståelse af de sociale mediers forretningsmodeller og en dybere forståelse af den kommercielle overvågning på nettet og dens implikationer i et bredere samfundsperspektiv.

Denne betydningsbredde er ikke så overraskende. Internettets indtog på snart sagt alle privatlivets og samfundslivets domæner udfordrer i bred forstand vores etablerede praksisser og forestillinger om tingenes tilstand. I familieliv såvel som arbejdsliv, skoleliv, politik og kulturliv skaber netværksbaserede medier nye rammer og spilleregler, der tvinger os til at genoverveje domænets grundlæggende logikker: Hvad er en god læreproces, og hvad skal børn overhovedet lære i skolen? Hvad er et repræsentativt demokrati og kan det gentænkes i lyset af de muligheder for borgerinvolvering, netværksmedierne stiller os overfor? I den forstand er der intet overraskende i, at internettets omkalfatring af privatliv og samfundsliv i bredeste forstand også kalder på en bred debat om de nye kompetencer og typer af dannelse, det fordrer.

En ulempe er dog, at det kan blive uklart, hvad vi egentlig diskuterer, og at 'digital dannelse' kan have en tendens til at blive brugt som svaret på snart sagt alle problemer, netværksbaserede medier bringer med sig, og ofte som et uerkendt alternativ til andre politiske løsningsmodeller såsom politisk regulering. Et eksempel på dette kunne være debatten om kommerciel overvågning og datasikkerhed i lyset af 'Cambridge analytica'-skandalen og GDPR. En kritisk og reflekteret forståelse af 'surveillance capitalism' (Zuboff, 2015) og dens samfundsmæssige implikationer er naturligvis en udmærket egenskab og noget, man kunne ønske sig ved den digitale medborger anno 2018, men det er uklart, hvad selv den mest oplyste og kritisk reflekterende medborger kan stille op på egen hånd i lyset af ulovlig data-indsamling og datasikkerhed. Dette er problemstillinger, der bedst adresseres på et institutionelt og samfundsmæssigt plan.

Forvirringen om det digitale dannelsesbegreb og dets brede definition og anvendelse kan delvist tilskrives en fejlagtig oversættelse fra det engelske 'digital literacy'. Hvis man slår digital dannelse op i den danske version af Wikipedia, kan man for eksempel læse, at: 
Digital dannelse kommer af det engelske Digital

Literacy, som er et begreb der blev udarbejdet af Paul Gilster i 1997. På det tidspunkt formulerede han digital literacy som evnen til, at kunne bruge og forstå digitaliseret information. ${ }^{3}$

'Literacy' og dannelse er imidlertid ikke den samme ting. 'Literacy' er ligesom dannelse et relativt komplekst begreb med mange tolkninger og anvendelser, men i kraft af dets forankring i en mangeårig forskningstradition, finder man flere konkrete rammesætninger og diskussioner af begrebet. Eksempelvis skelner Barbara Gentikow mellem tre principielle tilgange til literacy: 1) Evnen til at læse og skrive, 2) mestringen af nationens kulturelle kanon, og 3) forståelsen af forskellige medieteknologiers grundlæggende virkemåde (Gentikow, 2007, s. 2). Gentikow baserer den sidstnævnte tilgang på Meyrowitz' distinktion mellem medier som kanal, grammatik og miljø og de typer af 'literacies', denne distinktion lægger op til (Meyrowitz, 1997, 1998). Som det fremgår, ligger vægten i 'literacy' på et færdighedsperspektiv i relation til kommunikation og medier. Disse færdigheder varierer ganske vist i deres bredde fra en simpel teknisk forståelse, evnen til at læse og skrive, til en bredere forståelse med fokus på medieteknologiers virkemåde. Ikke desto mindre er der langt fra disse definitioner og til den dannelsesforståelse, der indgår i den nationale debat. Denne forståelse falder i højere grad ind under det engelske begreb 'digital citizenship' eller 'det digitale medborgerskab'.

Der eksisterer naturligvis også overlap mellem 'literacy' og 'citizenship'. Eksempelvis peger den førnævnte 'mestring af nationens kulturelle kanon' til en vis grad i retning af det, man i dansk kontekst ville forstå ved dannelse. Endvidere har David Buckingham (2007) pointeret, at 'digital literacy'-begrebet ikke må reduceres til et spørgsmål om rene kompetencer, men også bør inkludere en mere kritisk reflekterende tilgang til information og medieteknologier i den digitale tidsalder.

3 https://da.wikipedia.org/wiki/Digital dannelse (tilgået den 13.06.18). 
I kontekst af den aktuelle artikel giver det dog god mening at etablere et analytisk skel mellem literacy/kommunikative færdigheder og citizenship/dannelse, da det så at sige gør det muligt at skelne mellem målet og midlerne. I det kommende vil jeg skelne mellem 'digital literacy' som de digitale kommunikative færdigheder, der understøtter og danner grundlag for 'digital citizenship' i forståelse af medborgerskab og handlemuligheder i det digitale samfund. Denne adskillelse gør det muligt at diskutere hvilke kommunikative færdigheder, der på forskellige historiske tidspunkter har muliggjort medborgerskab og deltagelse i skiftende samfundsmæssige kontekster og, i forlængelse af dette, hvilke kommunikative færdigheder og hvilken samfundsmæssig kontekst, det giver mening at operere med i dag.

I de kommende afsnit vil jeg først etablere en bredere mediehistorisk kontekst med udgangspunkt i den teoretiske gruppering, der går under betegnelsen 'medium theory'. Vægten vil være på, hvordan forskellige medie- og kommunikationsteknologier giver anledning til forskellige typer af kommunikation, handling og social organisering, og hvordan de på den måde betinger samfundsstrukturerne og de individer, der bebor dem. I forlængelse af dette vil jeg skitsere hovedtrækkene i 'new literacy studies', og hvordan denne forskningstradition udvider 'literacy' til en flerhed af praksisser og modaliteter. Jeg vil argumentere for, at 'multimodale læsepraksisser' udgør en mulig vinkel på digitale kommunikative færdigheder som en forudsætning for digitalt medborgerskab, men at den historiske periodisering, 'medium theory' repræsenterer, åbner op for en mere konkret kobling mellem multimodale og digitale kommunikative færdigheder på den ene side og det digitale netværkssamfund, de skal understøtte dannelsen til, på den anden.

\section{Læsning og dannelse i et mediehistorisk perspektiv}

'Medium theory' repræsenterer en teoretisk gruppering indenfor medieforskningen, der deler en antagelse om, at medieteknologier i kraft af deres specifikke materielle egenskaber har en strukturerende virkning på det omgivende samfund. Mediernes særlige, tidslige, rumlige og sociale rammer har betydning for den menneskelige bevidsthed og for dannelsen og opretholdelsen af fællesskaber i samfundet - hvilket i sidste ende har indflydelse på mere overordnede samfundsstrukturer. 'Medium 
theory's historiske udgangspunkt stedfæstes typisk til Harold Innis' Empire and communications (2007 (1950)), som beskriver historiens imperier med udgangspunkt i de kommunikationsteknologier, der danner udgangspunkt for deres storhed og fald. 'Kommunikationsteknologier' inkluderer her materialer som ler, sten, papyrus og papir, og et centralt argument hos Innis er bl.a., at forskellige materialer har forskellig 'bias' mod holdbarhed i tid (fx runeristninger) eller bevægelse i rum (fx papir), der har betydning for imperiers relative stabilitet, konservatisme og evne til at overtage større territorier (Meyrowitz, 1994, s. 52). En anden central historisk figur er Marshall McLuhan (1964.b, 1964a), som med udtrykket 'The medium is the message' fastslår, at det er i mediets form snarere end dets indhold, at vi skal finde dets samfundsforandrende egenskaber. For eksempel er det ikke gennem en analyse af specifikke TV-serier og nyhedsprogrammer, man skal forstå tv-mediets samfundsmæssige betydning, men derimod hvordan det i sit sensoriske udtryk fremmer nye former for tænkning, handling og social organisering. McLuhan inspirerer bl.a. Walter Ong, der er særligt central i kontekst af denne artikel. I Orality and Literacy: The Technologising of the Word (Ong, 1982) beskriver Ong overgangen fra det orale til det skriftlige samfund, og hvordan skrivning på et helt fundamentalt plan omstrukturerer den menneskelige bevidsthed, bl.a. ved at reducere presset på den menneskelige hukommelse og ved at gøre synssansen til den centrale sans. Dette involverer bl.a. en social omorganisering af samfundets vidensressourcer såvel som en ny forståelse af, hvad der overhovedet repræsenterer viden i samfundet.

Det er karakteristisk for de nævnte medieteoretikere, at de adresserer et historisk 'makroniveau'. Det vil sige, de beskriver medieteknologiers betydning for den historiske udvikling på tværs af længerevarende perioder eller epoker, der betinges af den dominerende kommunikationsteknologi. Meyrowitz (1994) opsummerer disse perioder i henholdsvist et traditionelt oralt samfund, en skriftlig overgangskultur, en moderne printkultur og en global elektronisk kultur (s. 53-58). I den traditionelle orale kultur er samfundets vidensressourcer forankret i den menneskelige hukommelse. Dette skaber et relativt lukket samfund med fokus på mundtlig overlevering og på det fysiske fællesskab. Med den skriftlige overgangskultur nedbrydes dette orale fællesskab og muliggør symbolske fællesskaber, der kan eksistere på tværs af tid og rum. Denne skriftlige overgangskultur er dog både ujævn og langvarig, idet skriften som 'teknologi' (Ong, 1982) 
forudsætter kompetencer i bredere befolkningsgrupper og bred adgang til skrevne materialer for at slå igennem. Dette sker med den moderne printkultur, der for alvor nedbryder de orale og fysiske fællesskaber og baner vejen for bredere symbolske fællesskaber med nationalstaten som det helt afgørende moment: "Feudal societies based on face-to-face loyalties and oral oaths begin to give way to nation-states and to nationalism based on a shared printed language" (Meyrowitz, 1994, s. 55). Inden for denne teoretiske grupperings forståelsesramme er printkulturens fremkomst altså ikke alene historisk samtidig med det nationale fællesskab, den er en central forudsætning for det nationale fællesskab, idet nationalstaten netop opbygger sit symbolske fællesskab og sin identitet omkring det fælles skriftsprog.

Skriftsproget bliver som bekendt udfordret som dominerende kommunikationsform med fremkomsten af de elektroniske medier fra første halvdel af forrige århundrede og frem. Det er dette historiske brud, der udgør det centrale omdrejningspunkt for Marshall MacLuhans teoretiske arbejde, og det har vidtrækkende konsekvenser for det skriftbaserede nationale fællesskab, der opstår med den moderne printkultur. For det første markerer det en bevægelse bort fra den skriftbaserede tænkemåde og indvarsler en ny form for 'sekundær oralitet' (Holly, 1995) - en omorganisering af printkulturens sansehierarki med fokus på delte oplevelser (shared experience) fremfor tekstbaseret udveksling af viden. Derudover muliggør det en etablering af orale fællesskaber på tværs af tid og rum - og på tværs af de nationale fællesskaber. De elektroniske medier skaber i McLuhans terminologi en 'global landsby' (McLuhan \& Powers, 1989), og det er således allerede på dette historiske punkt, nedbrydningen af nationalstaten som det centrale organiseringsprincip tager sin begyndelse.

I kontekst af denne artikel bør man hæfte sig ved, at skolen som samfundsbærende institution opstår på samme tid som den moderne printkulturs fremkomst. Skolen danner medborgere til det nationale fællesskab gennem tilegnelse af skriftbaserede færdigheder, netop fordi det symbolske nationale fællesskab er organiseret omkring det fælles skriftsprog. Mestringen af læseog skrivefærdigheder bliver definerende for identiteten som medborger og en central forudsætning for handling og deltagelse i det nationale, printbaserede fællesskab. Når der opstår forskydninger i den dominerende medie- og kommunikationsteknologi, og printkulturen ophører med at være det dominerende medium, 
udfordres denne orden. Dette stiller ikke alene spørgsmålstegn ved de kommunikative færdigheder, skolen skal formidle, men også ved de typer af symbolske fællesskaber, identiteter og deltagelsesformer, de ideelt skal understøtte. Det er disse fællesskaber, identiteter og deltagelsesformer, der bør være styrende for diskussionen af, hvilke typer af færdigheder og kompetencer, skolen skal bibringe sine elever. Før jeg går længere ind i dette spørgsmål, vil jeg dog først adressere den udvikling, der har fundet sted, siden McLuhan indvarslede den globale landsby.

Meyrowitz' historiske periodisering slutter ved den postmoderne, elektroniske kultur, men det elektroniske mediesystem er som bekendt blevet fulgt af et nyt: computeren og de digitale netværksmedier. Disse medier udskiller sig dels ved at kunne simulere alle tidligere medier, orale og printbaserede såvel som elektroniske, og ved at introducere netværksbaserede kommunikationsmønstre, der bryder med de elektroniske mediers overvejende masse-transmitterende format (Jensen, 2013). Det første leder til nye, komplekse og multimodale teksttyper, der integrerer forskellige semiotiske systemer i det samme udtryk (Kress \& van Leeuwen, 2001). Det andet leder til nye kommunikative positioner, herunder en ophævelse af printkulturens og den elektroniske mediekulturs skarpe skel mellem afsender og modtager. Sidstnævnte udmønter sig, vel at mærke, ikke i en fuldkommen demokratisering og ligestilling af kommunikatører i det digitale mediesystem, kommunikationen er fortsat betinget af kommercielle interesser og infrastrukturelle ejerforhold (Bechmann \& Lomborg, 2013). Men det sætter ikke desto mindre nye rammer for de kommunikative færdigheder, den digitale medborger skal mestre.

Det centrale fokus for 'medium theory' er som nævnt mediesystemernes tidslige, rumlige og sociale rammer, og hvad det betyder for dannelsen og opretholdelsen af fællesskaber i samfundet. Manuel Castells beskriver i den forbindelse netværkssamfundets tidslige og rumlige logik som et 'space of flows' og en 'time-less time' (Castells, 200o). Ved 'space of flows' skal forstås, at netværkssamfundets rumlige logik er en netværkslogik med fokus på knudepunkter i netværk, som bryder med nationalstatens territoriale logik: "[...] the meaning and function of the space of flows depend on the flows processed within the networks, by contrast with the space of places, in which meaning, function, and locality are closely interrelated" (Castells, 2000, s. 14). 
Ved 'time-less time' skal forstås en nedbrydning af tidslige organisationsprincipper som for eksempel døgnets og menneskelivets cyklus. Den globale samtidighed i politisk handling og $\emptyset$ konomiske transaktioner betyder, at øjeblikket 'presses sammen', og netværksmediernes hypertekstuelle struktur betyder, at den tidslige linearitet brydes op eller 'de-sekventeres' så "[...] past, present, and future [occurs] in a random sequence (as in the electronic hypertext or in the blurring of life-cycle patterns, both in work and parenting)"(Castells, 2000, s. 13-14).

I begge tilfælde involverer de nye tidslige og rumlige rammer en udfordring for nationalstatens rumlige (territoriale) og tidslige (historiske) logik. Man kan sige, at netværkssamfundet fortsætter og accelererer den nedbrydning af det nationale fællesskab, der indvarsles med de elektroniske medier. Mens de elektroniske mediesystemer langt hen ad vejen blev formet ind i et nationalt symbolsk fællesskab, ikke mindst i deres public service varianter (se fx Scannell, 2018), undergraver de digitale netværksmedier for alvor nationalstaten som en afgrænset enhed i tid og rum og som centrum for økonomiske transaktioner og politisk magtudøvelse. Det skal dog tilføjes, at denne udvikling ifølge Castells ikke er entydig. Netværkssamfundets tids-, rumog organisationsformer eksisterer parallelt og i samspil med tidligere principper for tidslig, rumlig og social organisering. Faktisk pointerer Castells i den citerede artikel, at fremtidens centrale konflikter og opgør vil komme til at stå mellem de grupperinger, der befinder sig i centrum for den nye netværksbaserede virkelighed og drager fordel af den, og de grupperinger der forfordeles og skubbes ud i periferien i kraft af netværksmediernes omsiggribende forandringer. Sidstnævnte omfatter bl.a. nationale og etniske fællesskaber, der har det til fælles, at de er organiseret omkring det fysiske territorium.

Dette kan forklare en lang række begivenheder i den aktuelle globale verdensorden, og det føjer samtidig en central pointe til diskussionen om de symbolske fællesskaber, digitale kommunikative færdigheder ideelt skal sikre medlemskab af og deltagelsesmuligheder i. Denne pointe er, at det er et aktivt valg. Det globale netværkssamfund kan beskrives som et samfund, hvor mange forskellige mediesystemer og organisationsformer er i spil. Disse mediesystemers og organisationsformers konkrete konfiguration og relative magt er både betinget af deres materielle egenskaber og af, hvordan vi som borgere og som samfund handler i forhold til dem. Det er ikke noget, der er givet på for- 
hånd. Jeg vil vende tilbage til dette spørgsmål i min diskussion og tage stilling til, hvad det betyder for spørgsmålet om kommunikative færdigheder og dannelse til det digitale samfund. Først vil jeg dog introducere 'new literacy studies' og 'multimodale læsepraksisser' som mere konkrete bud på digitale kommunikative færdigheder.

\section{'New literacy studies' og multimodale læsepraksisser}

Jeg skrev i det foregående afsnit, at skolen som historisk institution opstår samtidig med printkulturens og det nationale fællesskabs fremkomst, og at dette gør læsning og skrivning til de indlysende kommunikative færdigheder, der skal understøtte medborgerskab og deltagelse i det printbaserede nationale fællesskab. Når printteknologien ophører med at være det dominerede mediesystem, opstår der behov for nye typer af kommunikative færdigheder, der ikke alene baserer sig på skrevne og trykte tekster. Et oplagt bud på, hvordan sådanne kommunikative praksisser kunne tage sig ud, er forestillingen om 'multimodale læsepraksisser', der indenfor de seneste årtier er blevet beskrevet og studeret indenfor rammerne af'new literacy studies'.

'New literacy studies' er ikke, som man måske ellers kunne tro, en respons på fremkomsten af nye medieteknologier, der udfordrer printkulturen som den dominerede medieteknologi i skolen. 'New literacy studies' er snarere en videnskabsteoretisk og ideologikritisk respons på den universalistiske og etnocentriske forståelse af læse- og skrivefærdigheder, der gør sig gældende indenfor den fortrinsvis kognitivt baserede forskning på området. Brian Street $(2013,1984)$ skelner i forlængelse af denne kritik mellem en autonom og en ideologisk tilgang til literacy eller læseog skrivefærdigheder. Den autonome tilgang bygger på læse- og skrivefærdigheder som et uafhængigt fænomen med forudsigelige effekter på tværs af kulturelle og sociale sammenhænge. Den tekniske forståelse af læse- og skrivefærdigheder, der gør sig gældende i denne tilgang, overskygger de mere overordnede kulturelle og politiske antagelser, den dækker over, og som ofte involverer, at én samfundsgruppe trækker sit verdenssyn ned over hovedet på andre samfundsgrupper. Til sammenligning repræsenterer den ideologiske tilgang en mere 'kulturelt-sensitiv' forståelse af læse og skrivefærdigheder som en praksis, der vari- 
erer fra sammenhæng til sammenhæng afhængig af de konkrete aktører og det konkrete formål (Street, 2013, s. 28-29).

Street forholder sig ikke i nævneværdigt omfang til 'medium theory' eller til Walter Ongs beskrivelse af overgangen fra orale kulturer til skriftkulturer (Ong, 1982), om end han lige så godt kunne have gjort det. Det er netop sådanne, mildt sagt, fejende historiske generaliseringer, 'new literacy studies' kritiserer gennem sin teoretiske og metodiske reorientering. Den teoretiske reorientering består i en sociologisk funderet forståelse af læseog skrivefærdigheder som konkrete 'praksisser', der kan variere fra kontekst til kontekst, og den metodiske reorientering består i introduktionen af etnografiske studier af sådanne praksisser i deres naturlige, empiriske sammenhænge. I denne proces gør 'new literacy studies' op med en entydig forståelse af Literacy, stavet med stort L og i ental, til literacies, forstået som de mange forskellige praksisser, læsning og skrivning kan dække over (Street, 2013, s. 35). Når Street og andre opererer med begrebet 'multiple literacies', skal det altså forstås som de mange forskellige typer af læse- og skrivepraksisser, skriftkulturen rummer, for eksempel rituel eller religiøs læsning, avislæsning, dagbogsskrivning og notetagning.

Til sammenligning adresserer begrebet 'multi-literacies' de mange 'modaliteter', disse praksisser kan omfatte. Ved modalitet skal forstås de semiotiske systemer, et udsagn kan inkludere, for eksempel håndskrift, trykt tekst, billeder, video, lyd, animation, programmeret adfærd etc. Læse- og skrivepraksisser kan således inkludere flere semiotiske systemer såsom skrift, tegning og foto. Denne erkendelse har ledt til introduktionen af nye typer af 'literacies' baseret på de semiotiske systemer, de involverer, herunder 'visual literacy', 'computer literacy', 'graphical literacy' og, ikke mindst, 'multimodal literacy' (Jewitt \& Kress, 2003). Forestillingen om 'multi-literacies' opstår således som en undergruppering af 'new literacy studies', der undertiden går under betegnelsen 'New London Group' (Street, 2009), og som netop har flerheden af modaliteter og deres varierende kombinationer som deres centrale anliggende. Street kritiserer denne teoretiske gruppering for dens mangel på etnografisk specificitet og dens tendens til at falde tilbage til tidligere tiders teknologiske determinisme og fejende generaliseringer. Samtidig bidrager denne gren af 'new literacy studies' med en række meget brugbare begreber til at forstå samspillet mellem forskellige udtryksformer i konkrete praksisser samt, ikke mindst, en række bud på en 
konkret 'pedagogy of multi-literacies' (Street, 2009). Dette omfatter begreber som 'multimodale diskurser' (Kress \& van Leeuwen, 2001), 'multilineære læsestier' (Kress, 2003) 'hybridisering' af tekstuelle praksisser (Mills, 2010) og tekster som spor af handling (Pahl \& Rowsell, 2012) samt konkrete bud på, hvordan dette kan omsættes til undervisning i skolen. 'New literacy studies' er altså et oplagt sted at begynde, hvis man vil udvide det kommunikative repertoire i klasseværelset. I kontekst af denne artikels fokus på dannelse til det digitale samfund, har 'new literacy studies' dog også nogle begrænsninger, som jeg vil adressere i den kommende diskussion.

For det første er 'new literacy studies' blev kritiseret for sit omfattende fokus på det lokale (Brandt \& Clinton, 2002). I kraft af sit udgangspunkt i etnografisk metode og situerede praksisser, er repræsentanter for denne forskningstradition utilbøjelige til at komme med mere generelle udsagn om læse- og skrivefærdigheder på tværs af sociale og kulturelle sammenhænge. Brandt og Clinton argumenterer således for, at 'literacy theory' bør være klar til at operere med de mere 'autonome' aspekter af læsebegrebet uden at falde tilbage i en autonom forståelse af literacy (Street, 2012, S. 41). Dette er en relativt klassisk kritik, der kan rettes imod alle typer af kvalitativ, etnografisk forskning, og den handler om den bredere anvendelse af den kvalitative forsknings fund og konklusioner (Flyvbjerg, 2006). I forlængelse af denne artikels fokus på dannelsen til det digitale samfund, involverer det omfattende fokus på lokale sammenhænge imidlertid også en anden problemstilling, nemlig den manglende diskussion af disse situerede praksissers rolle i relation til medborgerskab og deltagelse i bredere samfundsmæssig sammenhæng.

Endvidere adresserer Street New London Groups teknologiske determinisme og fejende generaliseringer, herunder de empirisk udokumenterede udsagn vedrørende den såkaldte 'new work order', som de multimodale læsepraksisser skal være en respons på. Hvor underbygget er i praksis den samfundsversion (eller måske snarere samfundsvision) New London Group bygger deres argument for multimodale læsepraksisser på (Street, 2009)? I begge tilfælde kan et 'medium theory'-perspektiv bidrage med relevante forklaringsrammer, og dette vil være genstanden for min diskussion. 


\section{Diskussion og konklusion: Dannelse til hvilket samfund?}

Jeg har i de forløbne afsnit skitseret to forskningstraditioner med relevans for spørgsmålet om multimodale læsepraksisser og dannelse til det digitale samfund, nemlig 'medium theory' og 'new literacy studies'. Der er for begges vedkommende tale om mangeårige og omfattende traditioner, som umuligt kan beskrives i deres helhed, så jeg har valgt at sætte fokus på de aspekter, der er relevante for den aktuelle diskussion: Hvilke kommunikative færdigheder er en forudsætning for identitet og deltagelse i det digitale netværkssamfund?

'Medium theory' bidrager i forlængelse af dette spørgsmål med et bredere historisk perspektiv, der kan forklare, hvorfor læsning, skrivning og medborgerskab historisk set er blevet betragtet som tæt forbundne. Dette skyldes netop den moderne skriftkulturs kommunikative orden, hvor nationalstaten er organiseret omkring det fælles skriftsprog, og mestringen af dette skriftsprog er en forudsætning for medlemskab og deltagelse i nationalstaten. Når denne orden erstattes af en ny, er det derfor relevant at spørge, hvilke nye kommunikative færdigheder der skal understøtte medlemskab og deltagelse i samfundet.

Foruden denne historiske betragtning kan 'medium theory' bidrage med en specifik forståelse af sammenhængen mellem dominerende mediesystemer og samfund, som vedrører den måde, medierne i kraft af deres rumlige og tidslige egenskaber sætter bestemte rammer for social organisering. Det har betydning for etableringen af sociale fællesskaber i bredeste forstand, og det er på den måde ikke alene de kommunikative kompetencer, men også karakteren af selve fællesskabet, som må tages op til diskussion: Hvad er det digitale netværkssamfund? Hvor går dets grænser, hvilke typer af identiteter og deltagelsesformer involverer det?

'New literacy studies' bidrager i forhold til dette med en relevant kritik af 'medium theory's blinde punkter. Dette vedrører den indbyggede etnocentrisme og, i kontekst af denne artikel, relativt universalistiske forståelse af læsepraksisser. 'New literacy studies' nuancering og 'pluralisering' er både et godt udgangspunkt for at nuancere en del af de antagelser, der ligger til grund for 'medium theorys' historiske periodisering, og for at reflektere over læse- og skrivefærdigheder som et historisk foranderligt begreb, der må defineres i relation til den aktuelle 
kontekst. Her bidrager 'new literacy studies' med konkrete bud på en 'pedagogy of multiliteracies' (Street, 2009), der rummer meget gode perspektiver på, hvordan digitale færdigheder kan gribes an i kombination med andre kommunikative færdigheder i skolen. 'New literacy studies' har dog sit primære teoretiske og empiriske fokus på praksisser i lokale sammenhænge og adresserer ikke spørgsmålet om færdighederne i relation til en bredere samfundsmæssig kontekst. Argumentet for multimodale praksisser bygger ganske vist på en specifik forventning om et fremtidigt arbejdsmarked, men denne er, som Street påpeger, ikke specielt velunderbygget.

Her kan Castells' beskrivelse af netværkssamfundet trækkes ind som et relevant perspektiv. Castells' teoretisk, historisk og empirisk velunderbyggede teori om netværkssamfundets egenskaber er et godt udgangspunkt for en refleksion over de typer af fællesskaber, digitale kommunikative færdigheder skal understøtte. Dette samfund kan betegnes ved en tidslig og rumlig logik, der på et fundamentalt niveau udfordrer nationalstaten som territorialt princip, herunder nationalstaten som ramme for $ø$ konomisk aktivitet og politiske beslutninger. Til en begyndelse kan vi altså fastslå, at nationalstaten som fællesskab betragtet er en utilstrækkelig ramme, hvis vi ønsker at danne medborgere til det digitale samfund.

Samtidig pointerer Castells dog, at netværkssamfundets tids-, rum- og organisationsformer eksisterer parallelt og i samspil med tidligere principper for tidslig, rumlig og social organisering. Nationalstaten er, som bekendt, ikke ophørt med at eksistere, men den eksisterer på nye vilkår i det globale netværkssamfund. På denne måde involverer netværkssamfundet i Castells' beskrivelse en samtidig eksistens af flere fællesskabs- og magtformer, der til tider er i indbyrdes konkurrence og konflikt. Dette indebærer på den ene side, at fællesskabet til et vist udtryk er et aktivt valg - vi kan vælge at bevare det nationale fællesskab, eller i hvert fald de dele af det nationale fællesskab som stadig er meningsfulde, og vi kan vælge de ikke-nationale fællesskaber, som muliggøres i kraft af netværksteknologiens opløsning af tidslige og rumlige logikker.

Det er ikke givet, at dette bør indebære en fuldstændig opgivelse af nationalstaten som relevant kulturelt og politisk fællesskab. Om end nationalstaten er ophørt med at være en dominerende ramme for økonomiske transaktioner (Castells, 1996), er den fortsat en central ramme for udøvelse af legitim po- 
litisk magt, hvilket må siges at være en nøglesten i demokratiet. I forlængelse af denne karakteristik er dannelsen til det digitale samfund ikke en total fraskrivelse af traditionelle dannelses- og kommunikationsformer, men derimod evnen til at forholde sig kritisk og refleksivt til en flerhed af fællesskaber og magtprincipper og at kunne tage del i dem. Forskellige typer af kommunikative færdigheder og kompetencer giver mulighed for medlemskab samt deltagelse i forskellige typer af fællesskaber - lokale såvel som nationale og globale. Skolen bør indoptage nye typer af kommunikative praksisser, herunder de multimodale og digitale, ikke fordi det nye pr. definition er bedre, eller at fremtidens arbejdsmarked forventes at antage bestemte former, men fordi skolens elever som fremtidige medborgere skal kunne deltage og forholde sig aktivt medskabende til det digitale netværkssamfunds mange mulige fællesskaber. Her er det klassiske nationale fællesskab ikke længere det eneste relevante eller naturlige, men en af de mange måder man kan indgå i samfundet på.

\section{Referencer}

Bechmann, A. \& Lomborg, S. (2013). Mapping Actor Roles in Social Media: Different Perspectives on Value Creation in Theories of User Participation. New Media \& Society, 15(5), 765-81. https://doi.org/10.1177/1461444812462853

Brandt, D. \& Clinton, K. (2002). Limits of the Local: Expanding Perspectives on Literacy as a Social Practice. Journal of literacy research, 34(3), 337-56.

Buckingham, D. (2007). Digital Media Literacies: Rethinking Media Education in the Age of the Internet. Research in Comparative and International Education, 2(1), 43-55. https://doi.org/10.2304/rcie.2007.2.1.43

Castells, M. (1996). The Information Age: Economy, Society, and Culture. Volume I: The Rise of the Network Society. Oxford: Blackwell.

Castells, M. (2000). Materials for an Exploratory Theory of the Network Society. The British journal of sociology, 51(1), 5-24. https://doi.org/10.1111/ j.1468-4446.2000.00005.x

Flyvbjerg, B. (2006). Five Misunderstandings about Case-Study Research. Qualitative, 12(2), 219-45. DOI: 10.1177/10778004,05284363

Gentikow, B. (2007). The Role of Media in Developing Literacies and Cultural Techniques. Nordic journal of digital literacy, 2(02), 78-96.

Holly, W. (1995). Secondary Orality in the Electronic Media. Aspects of oral communication (s.340-63). Berlin: Walter de Gruyter.

Innis, H. A. (2007). Empire and Communications. Lanham: Rowman \& Littlefield.

Jensen, K. B. (2013). Medier og samfund. København: Samfundslitteratur.

Jewitt, C. \& Kress, G. R. (2003). Multimodal Literacy. New York: Peter Lang.

Kress, G. \& van Leeuwen, T. V. (2001). Multimodal Discourse: The Modes and Media of Contemporary Communication. London: Hodder Education.

McLuhan, M. (1964a). The Medium Is the Message. San Francisco: HardWired. McLuhan, M. (1964,b). Understanding Media: The Extensions of Man. Boston: MIT Press. 
McLuhan, M. \& Powers, B. R. (1989). The Global Village: Transformations in World Life and Media in the 21st Century. Oxford: Oxford University Press. Meyrowitz, J. (1994). Medium Theory. I: D. Crowley \& D. Mitchell (Red.), Communication Theory Today (s. 50-77). Stanford, CA: Stanford University Press.

Meyrowitz, J. (1997). Tre Paradigmer i Medieforskningen. MedieKultur. Journal of media and communication research, 13(26), 56-69. https://doi. org/10.7146/mediekultur.v13i26.1090

Meyrowitz, J. (1998). Multiple Media Literacies. Journal of communication, 48(1), 96-108. https://doi.org/10.1111/j.1460-2466.1998.tbo2740.x

Mills, K. A. (2010). A Review of the 'Digital Turn' in the New Literacy Studies. Review of Educational Research, 80(2), 246-71. https://doi. org/10.3102/00346543103644.01

Ong, W. (1982). Literacy and Orality: The Technologizing of the Word. London \& New York: Methuen.

Pahl, K. \& Rowsell, J. (2012). Literacy and Education. London: SAGE Publications Ltd. http://dx.doi.org/10.4135/9781473915237

Scannell, P. (2018). Public Service Broadcasting and Modern Public Life. I: The Media, Journalism and Democracy, Routledge, 75106.

Street, B. (2013). New Literacy Studies. I: Language, Ethnography, and Education, Routledge, 33-55.

Street, B. V. (2009). Multiple Literacies and Multi-Literacies. I: R. Beard, D. Myhill, M. Nystrand \& J. Riley, The SAGE Handbook of Writing Development (s. 137-150). London: Sage. DOI: http://dx.doi.org/10.4135/9780857021069.n10 Zuboff, S. (2015). Big Other: Surveillance Capitalism and the Prospects of an Information Civilization. Journal of Information Technology, 3o(1), 75-89. DOI: 10.1057/jit.2015.5 


\section{Learning Tech - Tidsskrift for læremidler, didaktik og teknologi Udgives af Læremiddel.dk}

Learning Tech er et forskningstidsskrift, hvor alle artikler er forskerbedømt i form af dobbeltblindt peer review. Tidsskriftet bringer artikler, der rammer genstandsfeltet mellem læremidler, didaktik og teknologi, og hensigten er at spille en betydelig rolle som platform for den voksende skandinaviske læremiddelforskning.

\section{Redaktion}

Stig Toke Gissel, UCL Erhvervsakademi og Professionshøjskole (ansvarshavende redaktør)

Anne-Mette Nortvig, Professionshøjskolen Absalon

Bettina Buch, Professionshøjskolen Absalon

Hildegunn Juulsgaard Johannesen, University College Syd

Marie Falkesgaard Slot, UCL Erhvervsakademi og Professionshøjskole René Boyer Christiansen, Professionshøjskolen Absalon

Stefan Ting Graf, UCL Erhvervsakademi og Professionshøjskole Stine Reinholdt Hansen, UCL Erhvervsakademi og Professionshøjskole Thomas R.S. Albrechtsen, University College Syd

\section{Redaktionssekretær}

Trine Ellegaard, UCL Erhvervsakademi og Professionshøjskole

\section{Temaredaktion}

Stig Toke Gissel, UCL Erhvervsakademi og Professionshojskole Bettina Buch, Professionshojskolen Absalon

Stine Reinholdt Hansen, UCL Erhvervsakademi og Professionshojskole

\section{Design og grafisk tilrettelæggelse}

Trefold - grafisk design og kommunikation

\section{Tryk}

Narayana Press, Gylling

ISSN 2445-7981 (Tryk)

ISSN 2445-6810 (Online)

\section{Rettigheder}

(c) 2018 Læremiddel.dk og forfatterne

\section{Kontakt}

Læremiddel.dk, Niels Bohrs Allé 1, 5230 Odense M www.laeremiddel.dk 